Article

\title{
Experimental Analysis of Grease Friction Properties on Sliding Textured Surfaces
}

\author{
Xijun Hua ${ }^{1}$, Julius Caesar Puoza ${ }^{1, *}$, Peiyun Zhang ${ }^{1}$, Xuan Xie ${ }^{1}$ and Bifeng Yin ${ }^{2}$ \\ 1 School of Mechanical Engineering, Jiangsu University, Zhenjiang 212013, China; xjhua@ujs.edu.cn (X.H.); \\ pyzh@ujs.edu.cn (P.Z.); 18344715138@163.com (X.X.) \\ 2 School of Automotive and Traffic Engineering, Jiangsu University, Zhenjiang 212013, China; ybf@ujs.edu.cn \\ * Correspondence: deokaesar@gmail.com; Tel.: +86-156-0610-2187
}

Received: 4 October 2017; Accepted: 24 October 2017; Published: 27 October 2017

\begin{abstract}
There is comprehensive work on the tribological properties and lubrication mechanisms of oil lubricant used on textured surfaces, however the use of grease lubrication on textured surfaces is rather new. This research article presents an experimental study of the frictional behaviours of grease lubricated sliding contact under mixed lubrication conditions. The influences of surface texture parameters on the frictional properties were investigated using a disc-on-ring tribometer. The results showed that the friction coefficient is largely dependent on texture parameters, with higher and lower texture density resulting in a higher friction coefficient at a fixed texture depth. The sample with texture density of $15 \%$ and texture depth of $19 \mu \mathrm{m}$ exhibited the best friction properties in all experimental conditions because it can store more grease and trap wear debris. The reduction of friction is mainly attributable to the formation of a stable grease lubrication film composed of oil film, transfer film and deposited film, and the hydrodynamic pressure effect of the surface texture, which increases the mating gap and reduces the probability of asperity contact. This result will help in understanding the tribological behaviour of grease on a textured surface and in predicting the lubrication conditions of sliding bearings for better operation in any machinery.
\end{abstract}

Keywords: grease lubrication; laser surface texturing; friction reduction; texture density; texture depth; mixed lubrication

\section{Introduction}

With the rapid development of industrialization, friction and wear reduction between two sliding bodies requires the constant presence of a lubricant within the contact area in order to reduce and control friction and wear, thus reducing energy consumption, extending service life of mechanical systems and enhancing their reliability and safety [1-3]. In many situations the lubricant is automatically fed into the contact area by the relative movement of the friction pair itself. However, there are limitations that constrain the feeding of lubricants in some situations. For example: (i) when the load is high, the surfaces deform and adapt to each other and the interface between them becomes very tight; (ii) when the sliding distance is small relative to the extension of the contact area, especially in reciprocated sliding and fretting, the lubricant is not effectively fed into the interface; (iii) greases are not able to readily flow back (returning) into a contact zone in the same way as an oil lubricant due to their relatively low fluidity (high viscosity), in comparison with lubricating oil [4].

Laser surface texturing, which was pioneered by Etsion et al. $[5,6]$ as a surface-engineering technique, has emerged as a viable technology to keep grease where it is needed and to maintain lubrication for longer periods of time in order to address these concerns [7]. Applications of laser surface texturing on contacting parts such as piston ring-cylinder liners [8], cams/tappets [9], bearings [10], seals [11] and cutting tools $[12,13]$ can result in a significant reduction in friction and wear. Generally, surface texture may be positive, in that it protrudes out of the surface, or negative, 
for example dimples or holes. The dimpled surface texture is more popular due to its advantages in terms of micro-lubrication and ease of manufacturing. The role of surface texturing in improving the tribological properties varies based on the contact conditions-whether they are hydrodynamic (full), mixed, boundary or dry conditions. In the case of full hydrodynamic and mixed lubrication conditions, the micro-craters serve as micro-hydrodynamic bearings that increase the hydrodynamic pressure due to asymmetric pressure distribution, which results in greater hydrodynamic lift or larger fluid film thickness $[14,15]$. In mixed lubrication conditions, this additional lift in hydrodynamic pressure alters the balance between hydrodynamic and boundary lubrication, and consequently, the number of asperities in contact decreases, and friction and wear likewise decrease [16]. In boundary and dry contact lubrication conditions, these craters (dimples or grooves) act as lubricant micro-reservoirs for the continuous retention and supply of lubricant [17], or as micro-containers to capture wear debris and contamination particles so that plowing decreases [18,19]. Consequently, abrasive wear and friction are reduced. Sudeep et al. [7] experimentally compared the tribological and vibration behaviours of textured point contacts of bearing steel lubricated with oil and grease under starved conditions. It showed that the textured surface lubricated with grease yielded reductions in the friction coefficient and specific wear rate (SWR) of the balls as compared to the oil lubricated textured contacts. Additionally, reduction in the amplitudes of vibrations (at normal contact resonance frequencies) was observed with the grease lubricated textured surface in comparison with the corresponding oil lubricated cases. They further studied the vibration of lubricated textured point contacts of steel bearings due to surface topographies by simulation using fractals surface characterization method and experiment [20]. Their findings revealed that in the presence of surface textures, vibration reduced due to the enhanced value of damping in comparison with the contacts having smooth surfaces. Tang et al. [21] experimentally investigated the effects of surface texture parameters and roughness parameters on the frictional properties of grease lubricated spherical plain bearings under mixed lubrication conditions. The results showed that higher dimple depths and lower dimple densities would result in a distinct improvement of the friction coefficients. A maximum reduction of $55 \%$ was gained for the textured sample under running conditions, as compared with the un-textured one. Wang et al. [22] investigated the friction and wear behaviour of laser-textured surfaces sliding against a pin under the lubrication of polyurea grease containing various additives using a Universal Mechanical Tester (UMT-2MT) reciprocating friction tester. Results showed that the dimple patterns had lower friction coefficients than the un-textured surfaces, at a lower sliding speed of $0.015 \mathrm{~m} / \mathrm{s}$. However, the groove patterns had higher friction coefficients than those of the un-textured surfaces at all sliding speeds.

In the literature of previous studies, there is very little or no open research on the tribological performance of textured surfaces of mechanical components under grease lubrication as compared to that of oil. This is because grease behaviour is complicated and difficult to predict under operation due to the dual phases of its structure, namely solid and liquid. Secondly, the frictional performance of surface textures used on mechanical components under grease lubrication conditions in sliding motions is still not clear and needs further investigation. The basic objective of this research is to comprehensively establish the effects of surface texture parameters (texture density and texture depth) on friction in grease lubricated contacts. It is hoped that the understanding of the tribological behaviour of grease on a textured surface will help in predicting the lubrication conditions of sliding bearings for better operation in any machinery.

\section{Materials and Methods}

\subsection{Specimen}

The friction properties of laser textured surfaces were studied using a ring-on-washer configuration. In this respect, a stationary ring on a rotating disc were prepared as experimental specimens from commercially available alloys of copper (ZCuPb30) and bearing steel (GCr15) 
respectively. The ring was $54 \mathrm{~mm}$ in outer diameter, $38 \mathrm{~mm}$ in inner diameter and $10 \mathrm{~mm}$ in thickness with a normal hardness of $56 \mathrm{HRC}$. Its contact surface was textured. The disc was un-textured on the contact surface. Its outer diameter was $53 \mathrm{~mm}$, while the inner diameter was $39 \mathrm{~mm}$ and the thickness was $5 \mathrm{~mm}$, with a hardness of 60-65 HRC. The picture and 2D diagram of the friction pair used in this research are shown Figure 1. Prior to surface texturing, the frontal surfaces of each specimen were ground and polished to obtain the desired surface roughness Ra of $0.05 \mu \mathrm{m}$ using a metallographic specimen polishing machine.
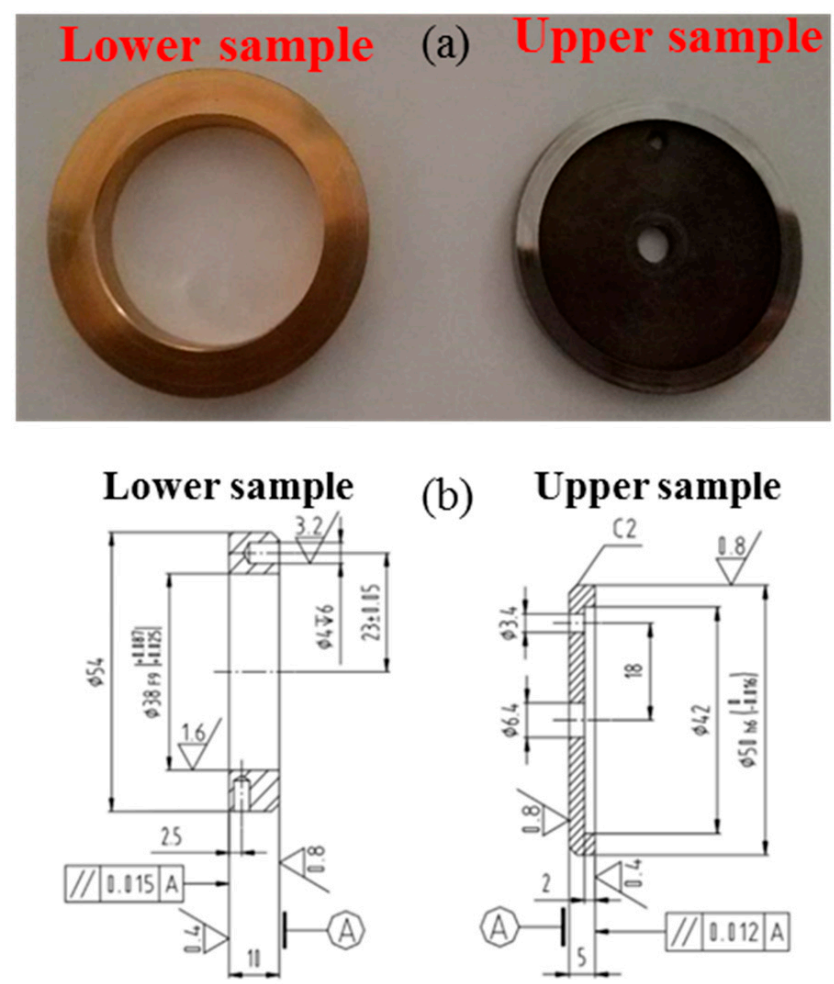

Figure 1. Picture and 2D diagram of friction pair.

In order to observe the effects of texture density and depth on different loads and sliding speed conditions, the reference grease should possess a high capacity for friction and wear, and it should be widely used in industrial applications. In this research, lithium-based high-quality multipurpose grease, which is often adequate for the lubrication of plain and rolling bearings, was used for the tribometer test. The detailed information of the reference grease is given in Table 1.

Table 1. Grease properties.

\begin{tabular}{|c|c|c|c|c|c|}
\hline Grease type & NLGI ${ }^{\text {a }}$ Grade & Thickener Type & Dropping Point ${ }^{\circ} \mathrm{C}$ & Base $\mathrm{C}$ & iscosity \\
\hline LGMT $^{\text {b }} 2 /($ pack size $)$ & 2 & Lithium & $>180^{\circ} \mathrm{C}$ & $\begin{array}{c}\text { @ } 40^{\circ} \mathrm{C} \\
110\end{array}$ & $\begin{array}{c}100{ }^{\circ} \mathrm{C} \\
11\end{array}$ \\
\hline
\end{tabular}

\subsection{Laser Surface Texturing}

Round micro-dimples in different texture densities and depths were manufactured on the flat side of the copper rings using high energy laser pulses in order to ablate the material by rapid melting and vaporizing. A green light Q-switched CEO®REA series Nd: YAG laser machine with extra double cavity, output wavelength of $532 \mathrm{~nm}$, pulse width of $\leq 70 \mathrm{~nm}$, laser power of $\leq 15 \mathrm{~W}$, spot diameter of $60 \mu \mathrm{m}$ and convex lens with focal length of $60 \mathrm{~mm}$ was used for the texturing process. Compared to 
the $1064 \mathrm{~nm}$ wavelength or continuous wave laser, this laser source produces less heat effect on the metallic material surface. Hence, the generation of recast layers is restrained effectively. The laser beam was reflected by three reflecting mirrors and then focused on the surface of the specimen by the convex lens during fabrication to optimize light-matter interaction. The specimens were clamp in a three key jaw fixture mounted on a motor controlled two-dimensional stage during the laser beam irradiation. The dimple depths were controlled by changing the laser power and the duration of the laser beam's ablating on the surface, while the dimple diameters were kept constant at $60 \mu \mathrm{m}$. The dimples on the surface of the ring specimen were uniformly arranged in a rectangular array as shown in Figure 2 and the design texture density $\left(T_{d}\right)$ calculated based on the formula

$$
T_{d}=\frac{A_{d}}{A_{t}} \times 100 \%=\frac{\pi D^{2}}{K \times L} \times 100 \%
$$

where $T_{d}$ is the texture area ratio (texture density); $A_{d}$ is the area of the dimple $\left(A_{d}=\pi D^{2}\right) ; A_{t}$ is the area of the micro dimple unit $A_{t}=K \times L ; D$ is the diameter of the dimple; $K$ and $L$ are the sides length of the micro-dimple unit or spacing between dimples, as shown Figure 2. The dimple parameters of the laser textured surface for the tribological test in this research are shown in Tables 2 and 3 while the samples are depicted in Figures 3 and 4. This dimple size was chosen based on past research by the authors [23] for effective grease lubrication. The bulges or burrs formed around the dimple rims during the laser texturing process were removed by a gentle polishing process. It has been experimentally demonstrated that these solidified bulges or burrs around the edges of the dimples have a negative effect on the tribological performance of contacting surfaces [24]. Finally, all specimens were measured in order to obtain 3D topography and 3D roughness parameters by using a noncontact 3D surface profiler (Wyko-NT1100, Veeco, New York, NY, USA).



Figure 2. Diagram of the micro-dimple array.

Table 2. Texture density parameters of laser surface texturing (LST) dimples.

\begin{tabular}{cccccc}
\hline Parameter & T-1 & T-2 & T-3 & T-4 & T-5 \\
\hline Texture density $(\%)$ & 5 & 10 & 15 & 20 & 25 \\
Dimple depth $(\mathrm{H} / \mu \mathrm{m})$ & 12 & 12 & 12 & 12 & 12 \\
Dimple diameter $(\mathrm{D} / \mu \mathrm{m})$ & 60 & 60 & 60 & 60 & 60 \\
\hline
\end{tabular}

Table 3. Texture depth parameters of LST dimples.

\begin{tabular}{cccccc}
\hline Parameter & H1 & H2 & H3 & H4 & H5 \\
\hline Texture density $(\%)$ & 15 & 15 & 15 & 15 & 15 \\
Dimple depth $(\mathrm{H} / \mu \mathrm{m})$ & 6 & 12 & 19 & 24 & 30 \\
Dimple diameter $(\mathrm{D} / \mu \mathrm{m})$ & 60 & 60 & 60 & 60 & 60 \\
\hline
\end{tabular}



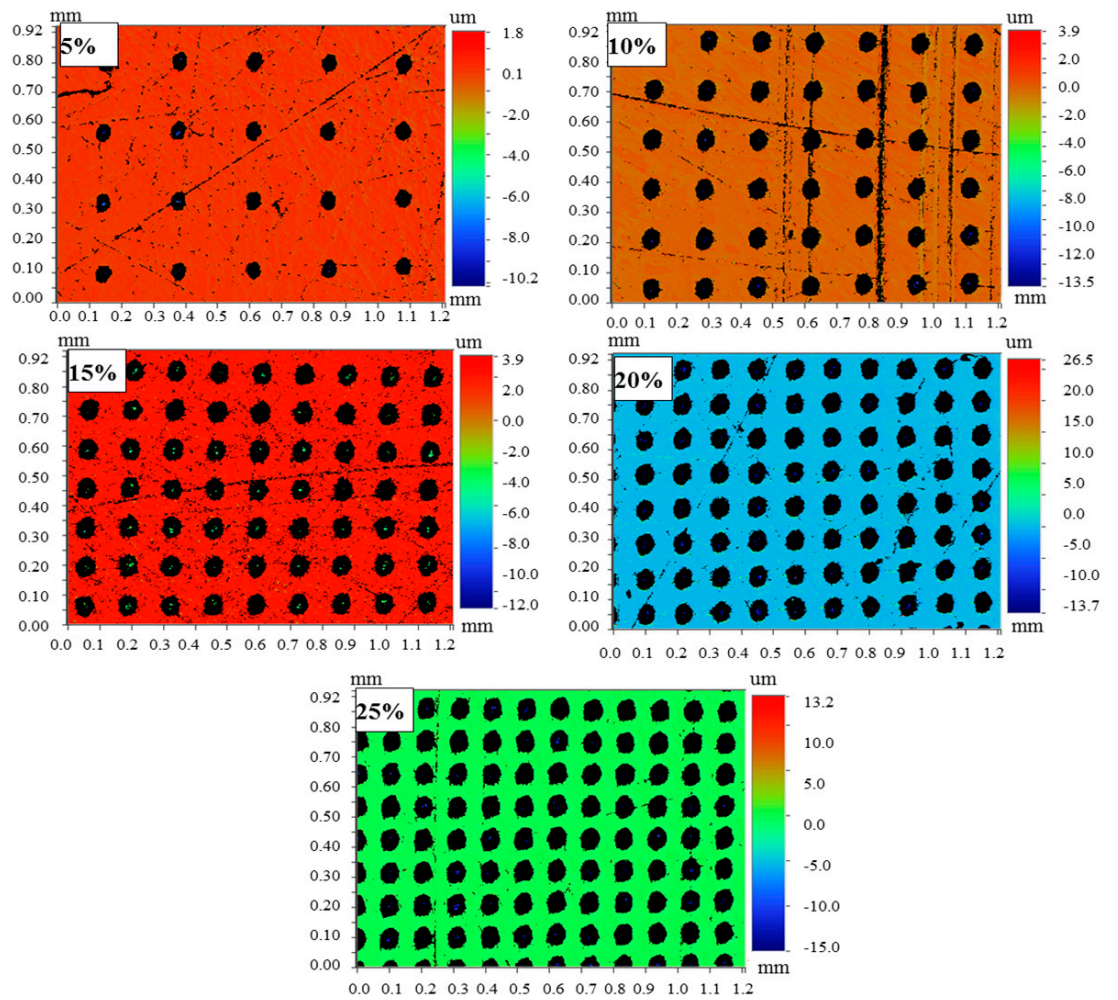

Figure 3. Surface topographies of different texture densities.
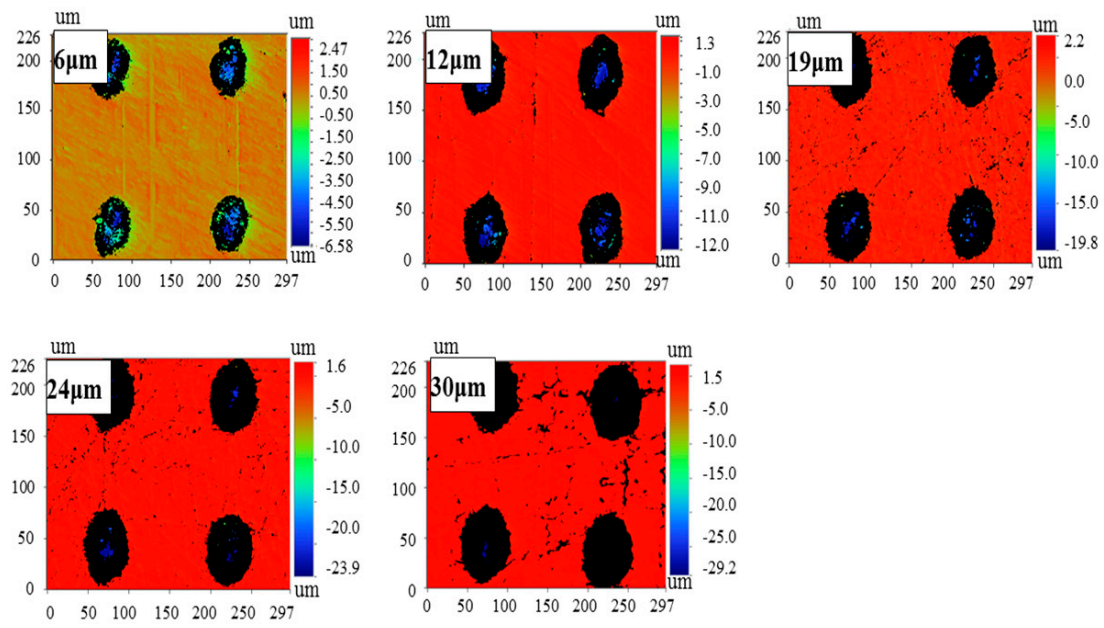

Figure 4. Surface topographies of different texture depths.

\subsection{Friction and Wear Test}

The tribological experiment was carried out in order to observe the friction behaviour of the sliding pair on an MMW-1A tribotester (Ji'nan Yihua Friction Testing Technology Co., Ltd., Ji'nan, China). The tribotester was composed of a driving spindle, driving disc holder, stationary disc holder, spindle drive system, operation panel, force sensor (inside), torque sensor (inside) and microcomputer data acquisition system, as depicted in Figure 5a and the test rig in Figure 5b. The test geometry was a rotating disc on ring (flat-on-flat) with Kingsbury-type lubricant entryways to ensure adequate distribution of grease along the sliding surface for proper lubrication. The disc was mounted on the driving disc holder which was connected to the driving spindle, while the textured ring was mounted on the stationary ring holder. The disc slid along the axis and rubbed against the fixed textured ring, 
and the sliding direction was perpendicular to the micro-dimples for all experiments. During the course of the test, grease was being added to the contact surface through the entryways. The friction coefficient between the disc and the ring samples was automatically and digitally recorded by the computer, while the force sensor and torque sensor measured the load and friction torque respectively. The coefficient of friction was measured against time, applied loads and speeds. The range of loads was from 100 to $500 \mathrm{~N}$ with a contact pressure of 0.46 to $2.31 \mathrm{MPa}$ and the range of speeds was from 100-500 rpm. In this research, 5 different loads and speeds were input to observe the frictional behaviour in different conditions. For checking the repeatability of the results, all experiments were conducted three times with complete sets of new contact pairs, and the maximum variation between the experimental values were controlled within $\pm 5 \%$. The data presented in this report represent the average of the test results. All the tests were conducted at atmospheric conditions (ambient temperature of $23 \pm 2{ }^{\circ} \mathrm{C}$ and relative humidity of $50-60 \%$ )

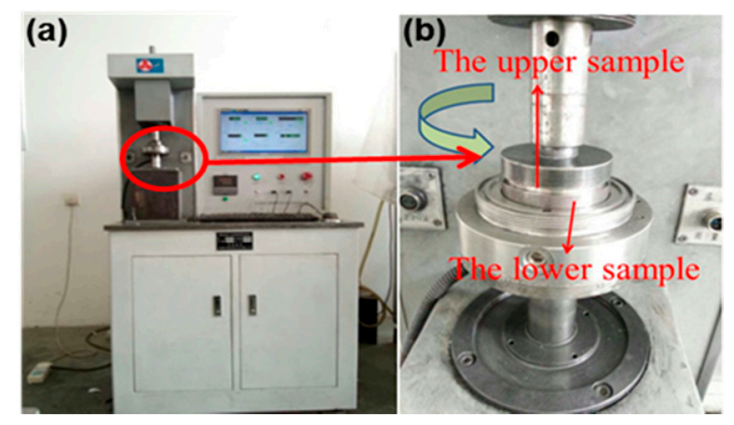

Figure 5. MMW-1A tribotester (a) and test-rig (b).

\section{Results and Discussion}

Under the present experimental conditions, the frictional behaviour of grease under textured surfaces in sliding conditions can be explained with the properties of grease and the influences of surface texture parameters.

\subsection{Effect of Texture Density on Coefficient of Friction}

The variations in friction coefficients of the disc and ring contact versus time for texture density are plotted in Figure 6a. A $200 \mathrm{~N}$ load and $100 \mathrm{rpm}$ sliding speed were applied for a duration of $30 \mathrm{~min}$ during the test. The results of the average steady state friction coefficient of the three repeated experiments are plotted in Figure $6 \mathrm{~b}$ at a texture depth of $\mathrm{H} 2=12 \mu \mathrm{m}$. In the initial phase of the test, the friction coefficients of the five samples were very high, of which texture density $5 \%$ and $25 \%$ were the highest. This is because grease exhibits semi solid colloidal characteristics, which makes it difficult to form a uniform stable lubrication film on the contact surface, resulting in a relatively poor lubrication effect. Secondly, the thixotropic properties of grease make the viscosity very high, and the thickness contributed friction resistance to the initial stage of the test. After the initial stage, the friction coefficients were greatly reduced and they reached a relatively stable state after a short period of time. This can be attributable to the formation of a more stable lubricating film on the contact surface by the relative movement of the friction pair and the even distribution of grease from the dimples. Additionally, the thixotropic properties of grease showed that the viscosity decreased with an increase in shear time, thus resulting in more fluidity and less resistance to friction. In Figure 6b, it can be seen that the texture density of $15 \%$ displayed the lowest friction coefficient of 0.16191 as compared to texture densities 5\% (0.21272), 10\% (0.19068), 20\% (0.17032) and 25\% (0.20861) under the experimental conditions. The reason for this is that the contact area between the disc and ring was sufficiently reduced but could still support the contact load with enough grease lubricant retained on the contact surface by the dimples [25]. This enabled the formation of a stable grease boundary 
film through mechanical entrapment and surface deposition of grease fibres on the contact surface. Additionally, the hydrodynamic action of the base oil from the dimples generated additional pressure to separate the sliding pair, thus reducing the friction. However, surface texture with texture densities of $5 \%$ and $25 \%$ had the highest coefficient of friction. This can be explained as a lack of sufficient grease lubricant on the contact surface to generate hydrodynamic pressure lift on the part of texture density $5 \%$, due to the small number of dimples. For the texture density $25 \%$, although there was more grease lubricant retained on the contact surface, the space between each dimple acted like a peak, which affected the film distribution by making it easy for it to flake away from the contact surface, resulting in a higher friction. Secondly, the load bearing area was drastically reduced, with the side effect far exceeding the grease lubrication effect on the contact surface. Thirdly, the thickener was ineffective, as it was unable to be absorbed on the contact surface to form a boundary film and was mostly found inside the dimples. Finally, the friction coefficient decreased with an increase in texture density up to a certain point, after which it began rising gradually as depicted in Figure 6b.


Figure 6. Friction coefficient versus time (a) and steady state friction coefficient (b) for texture density.

\subsection{Effect of Texture Depth on Coefficient of Friction}

Figure 7a shows the friction coefficient versus time for texture depth of specimens H1, H2, H3, H4 and $\mathrm{H} 5$ with a texture density of $15 \%$ (T-3), while Figure $7 \mathrm{~b}$ depicts the average steady state friction coefficient. A constant load and speed of $200 \mathrm{~N}$ and $100 \mathrm{rpm}$, respectively, were applied for a duration of $30 \mathrm{~min}$. The results show that the texture depth has an effect on friction. The friction coefficient of specimen $\mathrm{H} 5$ was higher than the other specimens. This is because the depth of dimples in specimen H5 was so deep that both the grease base oil and the thickener stayed in the bottom of the dimple and were very difficult to extrude on to the contact surface. This prevented the replenishment of the lost oil, which hindered the generation of hydrodynamic pressure and the formation of a boundary film. This made the film thickness decrease sharply, and the lubrication state of the friction pairs changed from fluid lubrication to boundary lubrication. This revelation is contrary to the research finding of Tang et al. [21] where higher dimple depths resulted in a lower friction coefficient. Conversely, for sample H1, the dimple depth was too shallow and the textured surface seemed to be close to a plain surface. This resulted in less grease storage by the dimples and led to a weak micro-hydrodynamic effect which increased the friction coefficient [26]. However, specimen H3, with the depth of $19 \mu \mathrm{m}$, had the lowest friction coefficient. This shows that specimen H3 had a moderate depth which was able to form a stable lubrication film composed of oil film, transfer film and deposited film on the contact surface in order to obtain a good lubricating effect. Secondly, the depth-to-diameter ratio $(\mathrm{H} 3 / \mathrm{d}=19 / 60=0.31)$ of specimen $\mathrm{H} 3$ was near to the optimum depth-to-diameter ratio range (0.2-0.28) reported by Zavos and Nikolakopoulos for a minimum friction coefficient [27]. Additionally, it can better capture and store the wear debris, thus reducing friction and wear between the contact pair. 



Figure 7. Friction coefficient versus time (a) and steady state friction coefficient (b) for texture depth.

\subsection{Effect of Load on Friction Coefficient}

The effects of load on friction behaviour of the SKF (Svenska Kullagerfabriken AB) grease lubrication were investigated by using the control variable method. Table 4 shows the parameters of the specimens selected to be investigated. The specimens that exhibited the lowest friction coefficient among the specimens presented in Sections 3.1 and 3.2 were selected for this series of experiments.

Table 4. Variable control method texture parameters of specimens.

\begin{tabular}{cccc}
\hline Test Number & V1 & V2 & V3 \\
\hline Texture density $(\%)$ & $10 \%$ & $15 \%$ & $15 \%$ \\
Texture depth $(\mathrm{H} / \mu \mathrm{m})$ & 12 & 19 & 24 \\
\hline
\end{tabular}

Figure 8 shows the effect of load on the friction coefficient of the specimens at a fixed speed of $100 \mathrm{rpm}$ and a duration of $20 \mathrm{~min}$. It can be seen that the friction coefficients of the specimens are reduced by increasing the normal load. At the initial load of $100 \mathrm{~N}$, the friction coefficient of all the three specimens was high, with that of the texture density of $10 \%$ (V1) being relatively smaller than that of the texture density of $15 \%$ (V2 and V3). This indicates that at low contact pressure, the surface roughness had a certain influence on the friction properties, since higher texture density led to higher surface roughness, and therefore a higher friction coefficient was more easily obtained. As the load increased, the friction coefficients of the three specimens were sharply reduced. This is attributable to the large quantity of oil being constantly released from the grease and the dimples into the sliding contact surface. This oil participated in the lubrication process and achieved a stable lubrication film due to the squeezing effect of the higher load. Additionally, as the load increased, the shear stress and the apparent grease viscosity also increased at a constant sliding speed. This increase the thickener concentration on the contact surface-which facilitated the formation of a protective film and the smoothing phenomena-are believed to be responsible for the reduction in friction. However, when the load increased past a certain point, the friction coefficients tended to be stable. This is because the excessive load damaged the grease fibre structure, making the grease fail, thereby affecting the friction coefficient. At this stage, the specimen V1 exhibited the highest friction coefficient while specimen V2 exhibited the lowest. This is because specimen V1 had a relatively smaller texture density and depth, with a low total storage capacity, resulting in less storage of the grease lubricant in the dimples as compared to specimens $\mathbf{V} \mathbf{2}$ and $\mathbf{V} 3$. This led to a relatively poor lubrication effect, thus the friction coefficient of specimen V1 was slightly higher. For specimens V2 and V3, although they had the same texture density, the depth of the dimples in specimen V2 $(19 \mu \mathrm{m})$ was relatively shallow. This more easily dispersed the grease from the dimples by the compression effect of the load, resulting in a lower friction coefficient. 




Figure 8. Friction coefficient versus applied load.

\subsection{Effect of Speed on Friction Coefficient}

Figure 9 shows the plots of friction coefficient versus sliding speed at different texture depths for a duration of $20 \mathrm{~min}$. The textured copper surfaces with texture depth of $\mathrm{H} 2, \mathrm{H} 3$, and $\mathrm{H} 4$ were selected for investigation and comparison. As can be seen from the diagram in Figure 9, the friction coefficient was low at the initial stage and, as the speed increased, the friction coefficient rose first and then decreased. This phenomenon can be categorized into three lubrication regimes: (1) the boundary lubrication regime; (2) the mixed film lubrication regime; and (3) the hydrodynamic lubrication regime. In the low speed range (100-200 rpm), there was enough grease on the contact surface at $100 \mathrm{rpm}$ for effective lubrication, hence the low friction coefficient. However, as the speed started to increase, some of the grease on the contact zone was easily thrown out. At this point, the grease supply directly affected the surface lubrication performance. The dynamic pressure effect of the surface texture was relatively weak and the lubricant film thickness was very thin. This directly increased the shearing of the contact surfaces, since the lubrication film had little effect and the friction coefficient of the specimen rose at this stage (region I). In the high speed range (200-400 rpm), the grease gradually exhibited a higher hydrodynamic pressure effect created by the influence of the dimples to lift the specimen. Thus, shearing between contact surfaces became smaller, and the friction coefficient decreased. At this stage, an extensive interaction of surface materials occurred, and the mixed film played a significant role in decreasing the friction coefficient (region II). In the speed range of $500 \mathrm{rpm}$ and above, the friction coefficient again rose slightly for specimens $\mathrm{H} 3$ and $\mathrm{H} 4$, due to the large amount of hydrodynamic pressure and a negligible sharing of surfaces. In this case, the contact surfaces were mainly separated by the grease fluid film, and the friction was governed completely by the shearing of the lubricant fluid film. The results show that under the present experimental conditions, specimen $\mathrm{H} 3$ with texture depth of $19 \mu \mathrm{m}$ had the lowest friction coefficient achievable at all sliding speeds, as depicted in Figure 9.

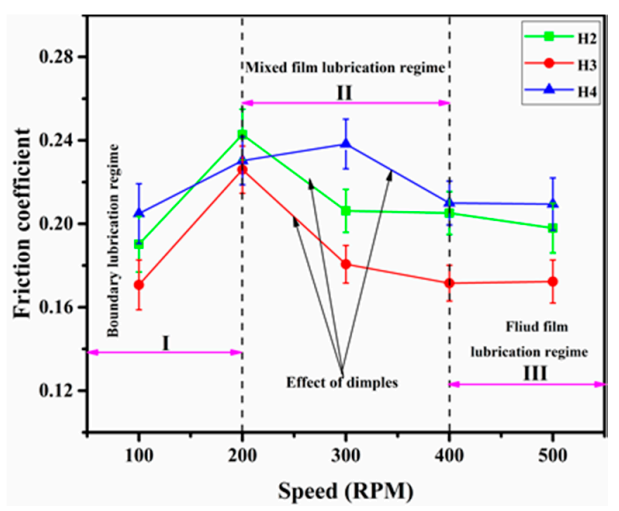

Figure 9. Friction coefficient versus speed for texture depth. 


\section{Conclusions}

In this research, a series of experiments were conducted to explore the effect of surface texture parameters on frictional properties of lithium-based grease under sliding condition. The circular dimples on the contact surface of the ring were designed with different dimple depths and densities. The experiments facilitated an understanding of the tribological behaviours of grease on textured surfaces. The conclusions drawn, based on the results under the present experimental conditions, are:

i. In general, the friction coefficient is largely dependent on texture parameters, with lower and higher texture densities resulting in a higher friction coefficient at a fixed texture depth.

ii. The sample with texture density of $15 \%$ (T-3) and texture depth of $19 \mu \mathrm{m}$ (H3) exhibited the best friction properties, experimentally, in all conditions because it could store more grease and trap wear debris.

iii. Higher load and speed increases the grease shear stress, apparent viscosity and thickener concentration, which facilitates the formation of a protective film and a smoothing phenomena, which are believed to be responsible for the reduction in friction.

iv. The reduction in friction by the surface texture and the main mechanism may be attributed to the hydrodynamic pressure effect, which increases the mating gap and reduces the probability of asperity contact.

Acknowledgments: The author(s) disclosed receipt of the following financial support for the research, authorship, and/or publication of this article: This study was supported by the National Natural Science Foundation of China (Nos. 51375211 and 51375213) and Primary Research \& Development Plan of Jiangsu Province (BE2017122).

Author Contributions: Julius Caesar Puoza conceived and designed the experiments with Xuan Xie under the supervision of Xijun Hua and Peiyun Zhang; Julius Caesar Puoza and Xuan Xie performed the experiments; Julius Caesar Puoza and Xuan Xie analyzed the data and discussed the results with Xijun Hua and Peiyun Zhang; Xijun Hua, Peiyun Zhang, Bifeng Yin and Julius Caesar Puoza contributed with reagents/materials/analysis tools; Julius Caesar Puoza wrote the paper; Xijun Hua, Peiyun Zhang, Bifeng Yin revised the paper.

Conflicts of Interest: The authors declare no conflict of interest.

\section{References}

1. Ligier, J.-L.; Noel, B. Friction reduction and reliability for engines bearings. Lubricants 2015, 3, 569-596. [CrossRef]

2. Sander, D.E.; Knauder, C.; Allmaier, H.; Damjanović-Le Baleur, S.; Mallet, P. Friction reduction tested for a downsized diesel engine with low-viscosity lubricants including a novel polyalkylene glycol. Lubricants 2017, 5, 9. [CrossRef]

3. Nikolakopoulos, P.G.; Bompos, D.A. Experimental measurements of journal bearing friction using mineral, synthetic, and bio-based lubricants. Lubricants 2015, 3, 155-163. [CrossRef]

4. Jacobson, S.; Kalvesten, E.; Pettersson, U. Effect of Surface Textures in Highly Loaded Grease Lubricated Reciprocating Sliding Contacts. In Proceedings of the 3rd World Tribology Congress, Washington, DC, USA, 12-16 September 2005.

5. Etsion, I.; Burstein, L. A model for mechanical seals with regular microsurface structure. Tribol. Trans. 1996, 39, 677-683. [CrossRef]

6. Etsion, I.; Halperin, G.; Greenberg, Y. Increasing Mechanical Seals Life with Laser-Textured Seal Faces; BHR Group Conference Series Publication; Mechanical Engineering Publications Limited: Maastricht, The Netherlands, 1997; pp. 3-12.

7. Sudeep, U.; Tandon, N.; Pandey, R. Comparisons of tribological and vibration behaviors of textured point contacts of bearing steel lubricated with oil and grease under starved conditions. J. Tribol. 2016, 138, 031504. [CrossRef]

8. Zhang, Y.L.; Zhang, X.G.; Wu, T.H.; Xie, Y.-B. Effects of surface texturing on the tribological behavior of piston rings under lubricated conditions. Ind. Lubr. Tribol. 2016, 68, 158-169. [CrossRef] 
9. Arslan, A.; Masjuki, H.H.; Varman, M.; Kalam, M.A.; Quazi, M.M.; Mosarof, M.H. Effect of change in temperature on the tribological performance of micro surface textured dlc coating. J. Mater. Res. 2016, 31, 1837-1847. [CrossRef]

10. Yu, R.F.; Li, P.; Chen, W. Study of grease lubricated journal bearing with partial surface texture. Ind. Lubr. Tribol. 2016, 68, 149-157. [CrossRef]

11. Kanakasabai, V.; Warren, K.H.; Stephens, L.S. Surface analysis of the elastomer in lip seals run against shafts manufactured with micro-cavity patterns. Proc. Inst. Mech. Eng. Part J J. Eng. Tribol. 2010, 224, 723-736. [CrossRef]

12. Sulaiman, M.H.; Christiansen, P.; Bay, N. The influence of tool texture on friction and lubrication in strip reduction testing. Lubricants 2017, 5, 3. [CrossRef]

13. Fang, S.; Llanes, L.; Bähre, D. Wear characterization of cemented carbides (wc-coni) processed by laser surface texturing under abrasive machining conditions. Lubricants 2017, 5, 20. [CrossRef]

14. Shen, C.; Khonsari, M. Effect of dimple's internal structure on hydrodynamic lubrication. Tribol. Lett. 2013, 52, 415-430. [CrossRef]

15. Tala-Ighil, N.; Fillon, M.; Maspeyrot, P. Effect of textured area on the performances of a hydrodynamic journal bearing. Tribol. Int. 2011, 44, 211-219. [CrossRef]

16. Tomanik, E. Modelling the hydrodynamic support of cylinder bore and piston rings with laser textured surfaces. Tribol. Int. 2013, 59, 90-96. [CrossRef]

17. Lu, P.; Wood, R.J.; Gee, M.G.; Wang, L.; Pfleging, W. The friction reducing effect of square-shaped surface textures under lubricated line-contacts-An experimental study. Lubricants 2016, 4, 26. [CrossRef]

18. Shum, P.; Zhou, Z.; Li, K. Investigation of the tribological properties of the different textured dlc coatings under reciprocating lubricated conditions. Tribol. Int. 2013, 65, 259-264. [CrossRef]

19. Zhang, H.; Zhang, D.; Hua, M.; Dong, G.; Chin, K. A study on the tribological behavior of surface texturing on babbitt alloy under mixed or starved lubrication. Tribol. Lett. 2014, 56, 305-315. [CrossRef]

20. Sudeep, U.; Tandon, N.; Pandey, R. Vibration studies of lubricated textured point contacts of bearing steels due to surface topographies: Simulations and experiments. Tribol. Int. 2016, 102, 265-274. [CrossRef]

21. Tang, Z.; Liu, X.; Liu, K. Effect of surface texture on the frictional properties of grease lubricated spherical plain bearings under reciprocating swing conditions. Proc. Inst. Mech. Eng. Part J J. Eng. Tribol. 2017, 231, 125-135. [CrossRef]

22. Wang, Z.; Xia, Y.; Liu, Z.; Hu, T. Friction and wear behaviour of laser-textured surfaces under the lubrication of polyurea grease containing various additives. Proc. Inst. Mech. Eng. Part J J. Eng. Tribol. 2011, 225, 139-150. [CrossRef]

23. Hua, X.; Puoza, J.C.; Sun, J.; Zhang, P.; Ji, J.; Wang, H.; Fu, H.; Kang, Z. Experimental analysis of friction and wear of laser microtextured surface filled with composite solid lubricant and lubricated with grease on sliding surfaces. J. Tribol. 2017, 139, 021609. [CrossRef]

24. Kovalchenko, A.; Ajayi, O.; Erdemir, A.; Fenske, G.; Etsion, I. The effect of laser surface texturing on transitions in lubrication regimes during unidirectional sliding contact. Tribol. Int. 2005, 38, 219-225. [CrossRef]

25. Gropper, D.; Wang, L.; Harvey, T.J. Hydrodynamic lubrication of textured surfaces: A review of modeling techniques and key findings. Tribol. Int. 2016, 94, 509-529. [CrossRef]

26. Peiyun, Z.; Xijun, H.; Zhihua, D.; Yonghong, F.; Wei, Z. Experimental research on grease lubrication properties of laser micro-texturing surface. Lubr. Eng. 2013, 38, 44-47.

27. Zavos, A.B.; Nikolakopoulos, P.G. Simulation of piston ring tribology with surface texturing for internal combustion engines. Lubr. Sci. 2015, 27, 151-176. [CrossRef]

(C) 2017 by the authors. Licensee MDPI, Basel, Switzerland. This article is an open access article distributed under the terms and conditions of the Creative Commons Attribution (CC BY) license (http:/ / creativecommons.org/licenses/by/4.0/). 